\title{
Rheology of high melt strength polypropylene for additive manufacturing
}

Jagenteufel, Ralf ; Hofstätter, Thomas; Kamleitner, Florian ; Pedersen, David Bue; Tosello, Guido; Hansen, Hans Nørgaard

Published in:

Advanced Materials Letter

Link to article, DOI:

10.5185/amlett.2017.1450

Publication date:

2017

Document Version

Publisher's PDF, also known as Version of record

Link back to DTU Orbit

Citation (APA):

Jagenteufel, R., Hofstätter, T., Kamleitner, F., Pedersen, D. B., Tosello, G., \& Hansen, H. N. (2017). Rheology of high melt strength polypropylene for additive manufacturing. Advanced Materials Letter, 8(6), 712-716.

https://doi.org/10.5185/amlett.2017.1450

\section{General rights}

Copyright and moral rights for the publications made accessible in the public portal are retained by the authors and/or other copyright owners and it is a condition of accessing publications that users recognise and abide by the legal requirements associated with these rights.

- Users may download and print one copy of any publication from the public portal for the purpose of private study or research.

- You may not further distribute the material or use it for any profit-making activity or commercial gain

- You may freely distribute the URL identifying the publication in the public portal

If you believe that this document breaches copyright please contact us providing details, and we will remove access to the work immediately and investigate your claim. 


\title{
Rheology of high melt strength polypropylene for additive manufacturing
}

\author{
Ralf Jagenteufel ${ }^{2}$, Thomas Hofstaetter ${ }^{1 *}$, Florian Kamleitner ${ }^{2}$, David B. Pedersen ${ }^{1}$ \\ Guido Tosello', Hans N. Hansen'
}

${ }^{1}$ Technical University of Denmark, Department of Mechanical Engineering, Kongens Lyngby, 2800, Denmark

${ }^{2}$ Vienna University of Technology, Institute of Materials Science and Technology, Getreidemarkt 9, 1060 Vienna, Austria

*Corresponding author. Tel: (+45) 452525 25; E-mail: thohofs@ mek.dtu.dk

Received: 11 October 2016, Revised: 02 December 2016 and Accepted: 12 December 2016

DOI: $10.5185 /$ amlett.2017.1450

www.vbripress.com/aml

\begin{abstract}
Rheological measurements of high melt strength polypropylene (HMS-PP) were used in order to generate master curves describing the shear-dependent viscosity in comparison to acrylonitrile butadiene styrene copolymer (ABS). The latter material showed specific disadvantages in terms of thermal stability, whereas HMS-PP showed a more stable behavior at the investigated temperatures. Hereafter, the material was used in a fused deposition modeling additive manufacturing process, focusing on the investigation of possible improvements of HMS-PP over ABS. Based on the extrusion parameters for ABS, adapted parameters for HMS-PP were determined using a fused deposition modeling test bench. The rheological survey clearly showed changes in the melt viscosity of both ABS and HMS-PP due to thermal degradation. However, the comparison of rheological data of the virgin materials with those of printed material showed negligible changes. This leads to the conclusion that the thermal degradation of HMS-PP and ABS during the fused deposition modeling process is negligible, due to the short exposure time to elevated temperatures. Copyright (C) 2017 VBRI Press.
\end{abstract}

Keywords: Additive manufacturing technology, ABS, fused deposition modeling, HMS-PP, rheology.

\section{Introduction}

Fused deposition modeling (FDM) is a method of additive manufacturing (AM) which operates by extruding thermoplastic material [1]. Herein a wide variety of filament materials can be used, however the most commonly used is Acrylonitrile butadiene styrene (ABS), followed by polycarbonate (PC), polylactic acid (PLA) and polyphenylsulfone (PPSF), among others [2]. ABS is produced by polymerizing acrylonitrile and styrene monomer in the presence of polybutadiene (PB) by emulsion or continuous mass technique, resulting in a $\mathrm{PB}$ rubber crosslinked by styrene-co-acrylonitrile (SAN) where the SAN to $\mathrm{PB}$ ratio can be varied [3]. The mechanical properties and thermal degradation processes of ABS have already been the subject of many studies, for example [4] and [5].

A different material, featuring similar good properties yet not being used in FDM is high melt strength polypropylene (HMS-PP) which is produced by grafting butadiene to the polypropylene chain to obtain long-chain branching [6]. The aim of this research contribution was to study the possibility of using this material for FDM. So, HMS-PP (Borealis WB $140 \mathrm{HMS}$ ) and ABS filament (Firstcom [3D001-1.7MM-NT.44MF]) were studied in a plate-plate rheometer to generate a full description of their melt-viscosity, and to show the rheological changes due to thermal degradation during extrusion. Furthermore, the impact of the degradation during extrusion in the printer should be examined by comparison of the rheological data of the printed and unprinted material.

\section{Background}

Viscoelastic liquids behave elastic and viscous at the same time. Depending on the velocity of deformation the elastic- or viscous component dominates the substances characteristics. Above the melting point $\left(\mathrm{T}_{\mathrm{m}}\right)$ (partially crystalline thermoplasts) and the glass transition temperature $\left(\mathrm{T}_{\mathrm{g}}\right)$, respectively (amorphous thermoplasts), polymers are viscoelastic liquids. To determine their socalled linear-viscoelastic region via amplitude sweep, the sample is placed in a plate-plate rheometer and deformed with a constant frequency and increasing strain. Within the linear-viscoelastic region a frequency sweep can be carried out with certain frequencies [1] to measure the according torsional moments and shear stresses in order to calculate the rheological relevant data storage modulus G', loss modulus G' and complex viscosity. Due to the Cox-Merz rule the frequency sweep covers a wide range of shear rates which is needed to study the liquid polymer properties during extrusion (high sear rates) and the end of extrusion and tearing off of the filament (very low shear rates) [7].

The time temperature superposition principle is a property which is only valid for certain viscoelastic 
liquids. It is characterized by the fact that rheological curves, measured at different temperatures, and plotted in double-logarithmic scale, are just shifted. If the temperature dependency of the material's relaxation time is equal, the material features thermo-rheological simple behavior. In this case a shifting factor $\mathrm{a}_{\mathrm{T}}$ along the frequency- and time axis can be calculated according to equation (1) [7].

$$
a_{T}=\frac{x_{T^{r e f}}}{x_{T}}
$$

Equation (1) $\mathrm{a}_{\mathrm{T}}$ is the shifting factor in $\mathrm{x}$-direction, $\mathrm{x}_{\mathrm{T}}{ }^{\mathrm{ref}}$ is the $\mathrm{x}$-coordinate of the crossover point at reference temperature and $\mathrm{x}_{\mathrm{T}}$ is the $\mathrm{x}$-coordinate of the crossover point of the measured curve.

For the rheological measurements is assumed that sample preparation took place in the same procedure for all measurements and can therefore be neglected for drawing conclusions.

\section{Experimental}

\section{Rheological measurements}

Rheological measurements were carried out with a plateplate rheometer Physica MCR 301. Therefore samples of $25 \mathrm{~mm}$ diameter and $1.2 \mathrm{~mm}$ height were produced by compression molding $\left(5 \mathrm{bar}, 180{ }^{\circ} \mathrm{C}\right)$ of the primary material, ABS filament and HMS-PP (Borealis WB 140 HMS) granulate. To verify the linear-viscoelastic region, amplitude sweeps were carried out at $170{ }^{\circ} \mathrm{C}$, $190{ }^{\circ} \mathrm{C}, 220^{\circ} \mathrm{C}$ and $250{ }^{\circ} \mathrm{C}$, respectively. According to the resulting graph, presented in (Fig. 1) linear viscoelasticity is fulfilled until a deformation of $20 \%$. However, frequency sweeps were carried out within a strain of $1-2 \%$.

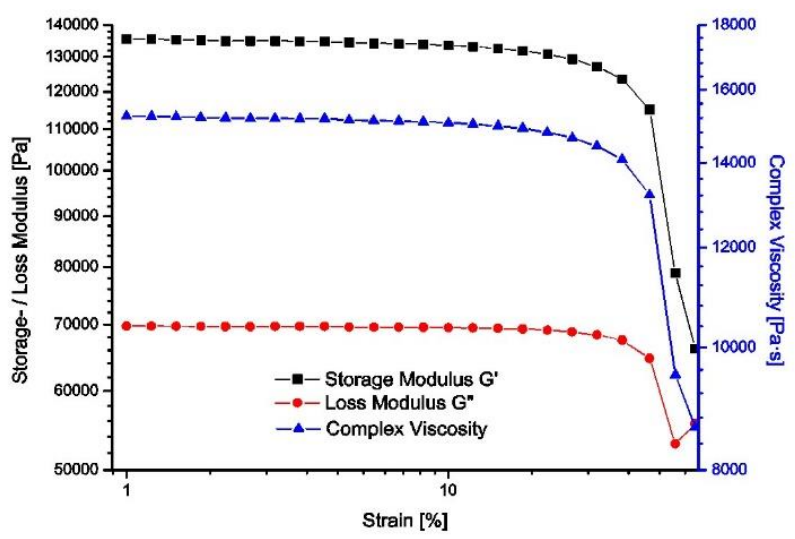

Fig. 1. Amplitude sweep of ABS measured at $170{ }^{\circ} \mathrm{C}$. Stress rates up to $20 \%$ are lying in the viscoelastic region. Graphs of measurements at higher temperatures as well as for HMS-PP are included in (Fig. I) in the section of supporting information.

The intention of the time sweeps for a period of 120 min was to check if the material would be stable enough to enable measurements under the desired conditions: technical nitrogen atmosphere and elevated temperatures of $170{ }^{\circ} \mathrm{C}, 190^{\circ} \mathrm{C}, 220^{\circ} \mathrm{C}$ and $250{ }^{\circ} \mathrm{C}$.
The main part of the rheological survey represented the frequency sweep measurements under the same conditions in order to calculate the master curves according to the time-temperature-superposition principle as well as comparing the "virgin" material prior to printing to printed probes.

\section{FDM-experiments}

Extrusion tests were carried out at the Fablab of the Technical University of Denmark (DTU) on the FDM test bench [8], which was designed to simulate the extrusion of FDM printing but was orientated horizontal. Therefore, the test bench was orientated vertically, so the extrusion took place in direction of gravitational force, the same way as extruders are usually orientated in 3D-Printers. The two different extruder types E3D-V6 with $0,35 \mathrm{~mm}$ nozzle and $\mathrm{J}$-Head with $0,4 \mathrm{~mm}$ nozzle, specifications can be seen in table 1, were utilized alongside the desktop 3D printer WANHAO Duplicator 4 [9] with $0,4 \mathrm{~mm}$ nozzle. Every extrusion was recorded with a microscope camera.

For extrusion experiments with HMS-PP, two filaments, HMS-PP 1,9 $\mathrm{mm}$ and HMS-PP 1,75 mm, were available. Deriving from the conversion process of granulate into filaments, their quality in terms of constant diameter and surface smoothness was absolutely distinct.

HMS-PP $1,9 \mathrm{~mm}$ showed a diameter fluctuation of around $\pm 0,3 \mathrm{~mm}$ and an opaque and rough surface. It was utilized to determine principal extruding behavior and the optimal extrusion temperature using the E3D-V6.

HMS-PP 1,75 mm showed diameter fluctuations below $\pm 0,03 \mathrm{~mm}$, higher surface smoothness and was equally opaque. It was used for extrusion experiments with the 3D-printer, since it was comparable to the commercial ABS 1,75 mm filament, unlike the HMS-PP 1,9 mm.

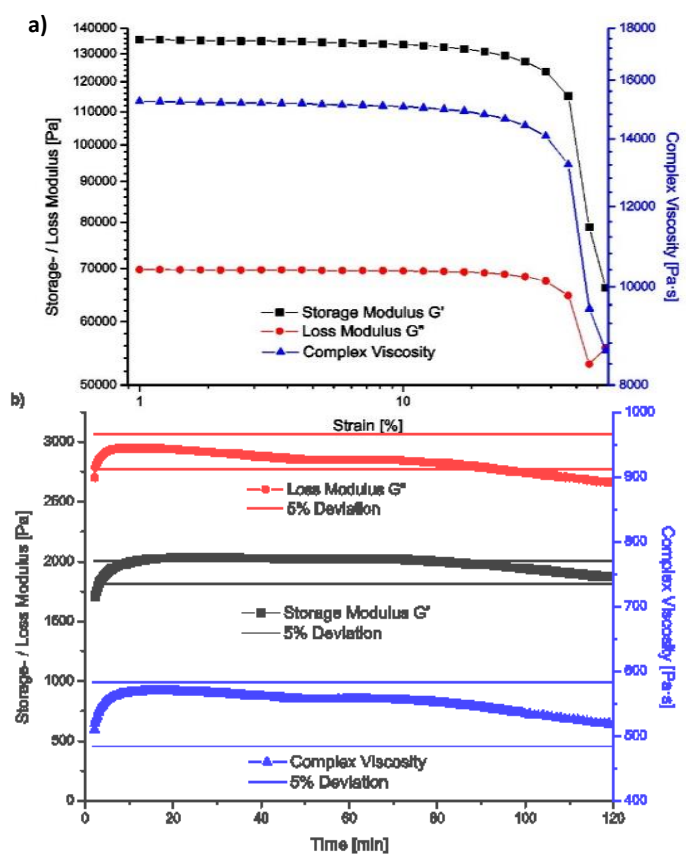

Fig. 2. (a) Time sweep of ABS at $180^{\circ} \mathrm{C}$ and (b)Time sweep of HMS$\mathrm{PP}$ at $250{ }^{\circ} \mathrm{C}$. ABS are stable at lower temperatures of $180{ }^{\circ} \mathrm{C}$ because the deviation of the complex viscosity is lower than $5 \%$. For HMS-PP this is true even at $250{ }^{\circ} \mathrm{C}$. 


\section{Results and discussion}

\section{Rheological measurements}

The measured time sweeps presented in (Fig. 2a, b) show that the deviation of the complex viscosity is below $5 \%$ for $\mathrm{ABS}$ up to temperatures of $180{ }^{\circ} \mathrm{C}$ and for HMS-PP up to $250{ }^{\circ} \mathrm{C}$. The increasing slopes for ABS in (Fig. 3) indicate that the conventional material for additive manufacturing is not as stable as the studied new material HMS-PP. ABS is being degraded due to the thermal energy which results in chain scission or cross-linking [5]. The decreasing trend for HMS-PP derives from further interconnections activated through the elevated temperature. This is due to the manufacture mechanism of HMS-PP, namely grafting butadiene to the polypropylene chain, where residues of the monomer stay present in the material [6].
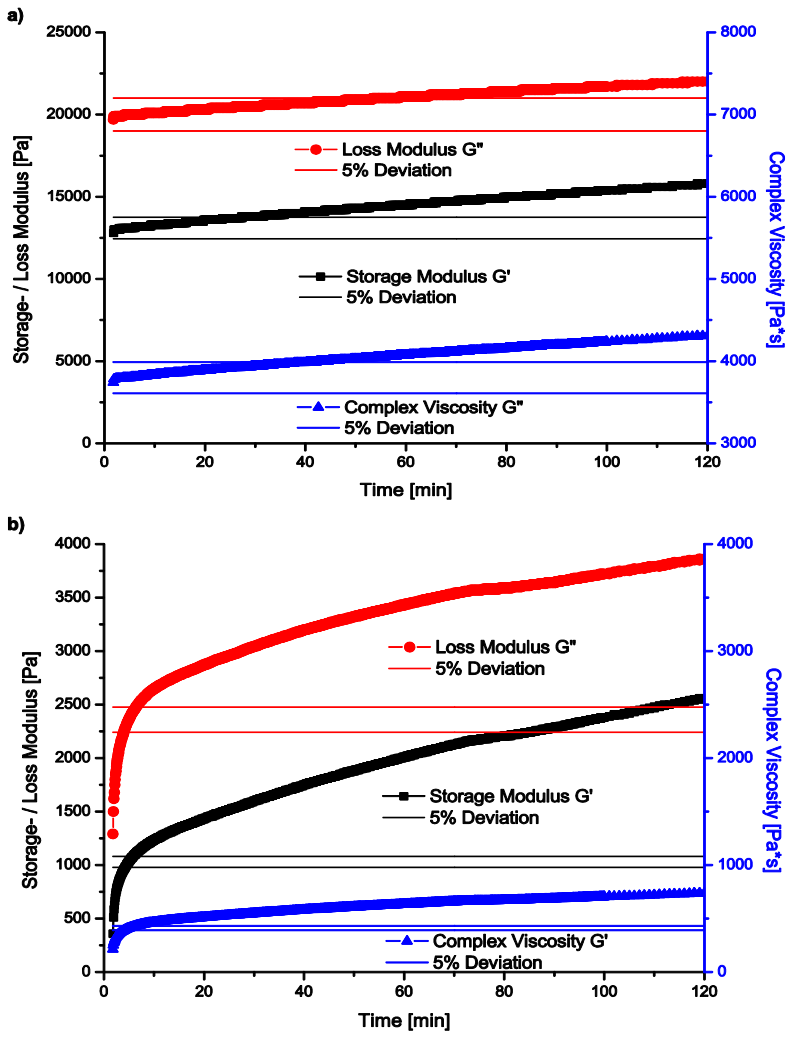

Fig. 3. (a) Time sweep of $\mathrm{ABS}$ at $220^{\circ} \mathrm{C}$, (b)Time sweep of $\mathrm{ABS}$ at $250{ }^{\circ} \mathrm{C}$. Increasing slopes indicate that the material undergoes further reactions.

The data points obtained through frequency sweeps at $170{ }^{\circ} \mathrm{C}, 220^{\circ} \mathrm{C}$ and $250{ }^{\circ} \mathrm{C}$, respectively, presented in (Fig. II) in the section of supporting information, were shifted according to their factor $\mathrm{a}_{\mathrm{T}}$ presented in Table 2.

Table 2. Parameter values for the calculation of the master curves.

\begin{tabular}{c|cccccc}
\hline \multicolumn{3}{c}{ ABS } & \multicolumn{3}{c}{ HMS-PP } \\
\hline $\mathrm{T}^{\circ} \mathrm{C}$ & 170 & 220 & 250 & 170 & 220 & 250 \\
$\mathrm{aT}$ & 9.127 & 0.177 & 0.041 & 4.485 & 0.555 & 0.195 \\
$\mathrm{a}^{\mathrm{corr}}$ & 7.000 & 0.135 & 0.043 & 2.400 & 0.400 & 0.090 \\
$\mathrm{~b}_{\mathrm{T}}$ & 1.710 & 1.000 & 1.000 & 1.170 & 0.820 & 0.550 \\
\hline
\end{tabular}

The crossover points were brought to superimpose with the reference temperature of $190{ }^{\circ} \mathrm{C}$ more precisely by optical correction, resulting in $\mathrm{a}_{\mathrm{T}}{ }^{\text {corr }}$. The final master curves (rectified by outliers) are presented in (Fig. 4).
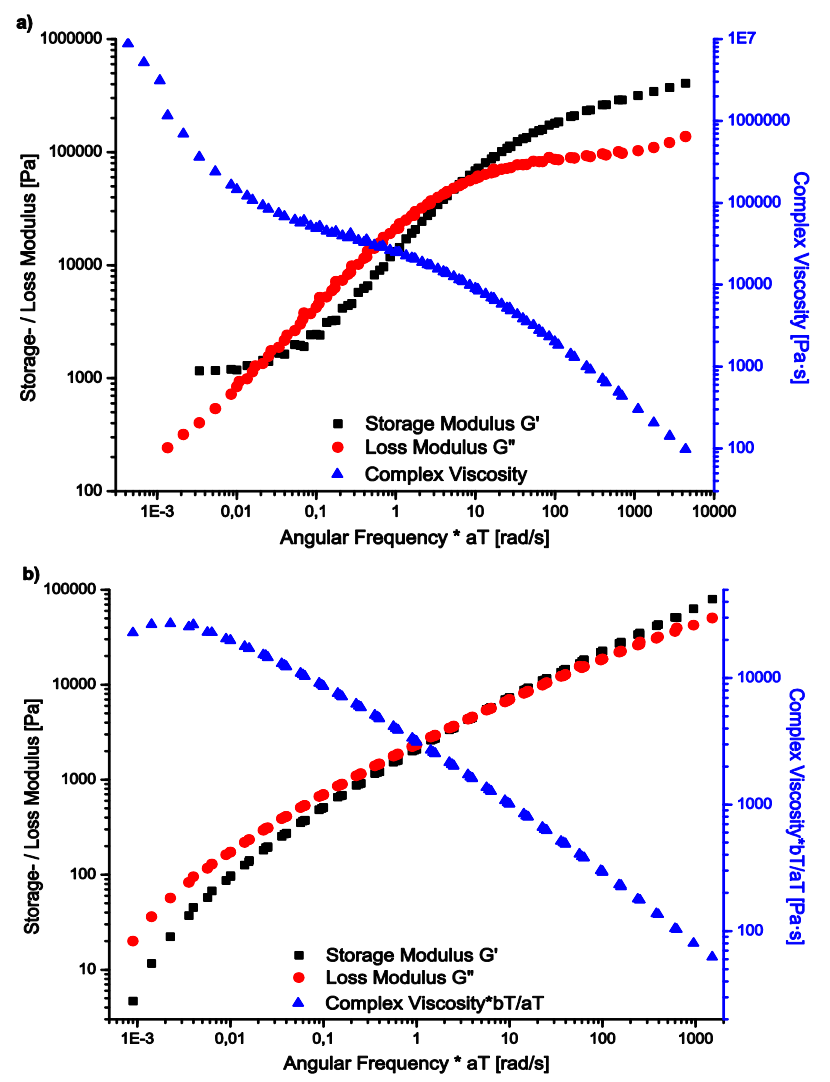

Fig. 4. (a) Master curve of ABS at $190{ }^{\circ} \mathrm{C}$, (b) Master curve of HMS-PP at $190^{\circ} \mathrm{C}$.

To determine if the degradation during the extrusion in the printer influenced the rheological properties significantly, G' and G" curves of printed material were plotted in comparison to "virgin" probes in (Fig. 5). It is easily seen that the loss modulus G" did not change notably, whereas the storage modulus $G^{\prime}$ shows some minor deviation for lower frequencies in both materials. The deviation in ABS is bigger than in HMS-PP but in general not significantly, so both materials are stable during extrusion. It has to be taken into account that the "virgin" data of HMS-PP represents granulate, which was fused into a filament prior to printing, resulting in two thermal treatments, whereas "virgin" ABS is the filament itself, so printing is the only thermal treatment. Furthermore, in the case of ABS two samples were extruded at different speeds (20 and $110 \mathrm{~mm}$ per minute), which did not result in any difference.

\section{FDM-experiments}

ABS tended to smudge the nozzle due to oozing, so there were difficulties obtaining clean straight fused filaments. After stopping the extrusion process, additional material flowed out of the nozzle due to heat and gravitation and formed a thin fused filament, which stuck to the hot nozzle. 

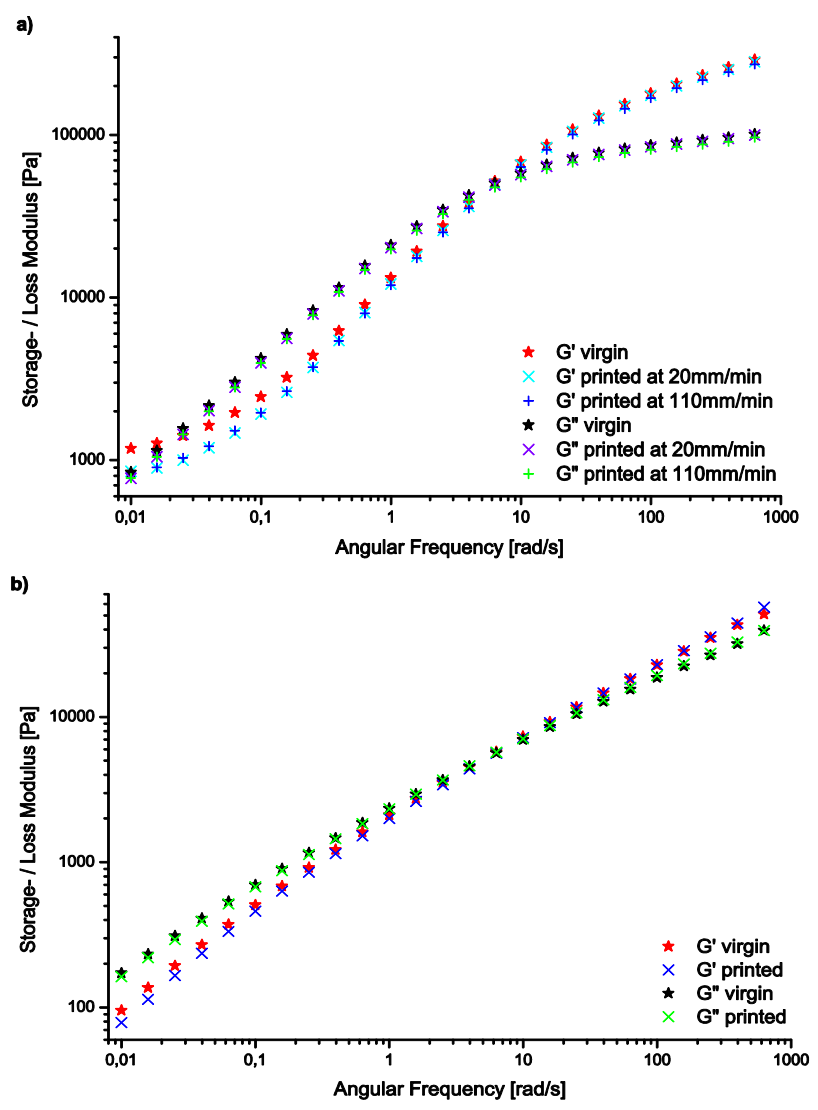

Fig. 5. (a)Comparison of virgin $A B S$ to printed $A B S$ measured at $190{ }^{\circ} \mathrm{C}$, (b)Comparison of virgin HMS-PP to printed HMS-PP measured at $190{ }^{\circ} \mathrm{C}$.

In case of no interaction between residues of preliminary extrusions ABS showed a very smooth and constant extrusion behavior where length and diameter of the fused filaments varied according to extrusion speed. Lower speed, for instance $22 \mathrm{~mm} / \mathrm{min}$ resulted in a longer dwelling time inside the nozzle and therefore in higher elongation due to gravitational force. Fused filaments extruded with up to $110 \mathrm{~mm} / \mathrm{min}$ resulted to be shorter and thicker. (Fig. III) in the section of supporting information graphically presents the connection of extrusion speed to fused filament length.

A good compromise of fast printing and thin filaments could be achieved using the J-Head at $243{ }^{\circ} \mathrm{C}$ set temperature with an extrusion speed between 60 and $80 \mathrm{~mm} / \mathrm{min}$. It was observed that the fused HMS-PP filament expands to a thickness of about $1 \mathrm{~mm}$ directly after the nozzle before solidification, resulting in thick filaments. Fused filaments with very small diameters, comparable to those of ABS, could be obtained by assisting the gravitational force through pulling down the fused filament. Contrary to ABS the fused HMS-PP filament tears off by itself after stopping the motor and the residual material contracts back into the nozzle. So there is no oozing and the nozzle tip is left clean. This behavior was observed at all examined temperatures between $160^{\circ} \mathrm{C}$ and $260{ }^{\circ} \mathrm{C}$ as well as with an extruding speed varying from $10 \mathrm{~mm} / \mathrm{min}$ to $140 \mathrm{~mm} / \mathrm{min}$. Images illustrating the HMS-PP and ABS extrusion are presented in (Fig. 6).
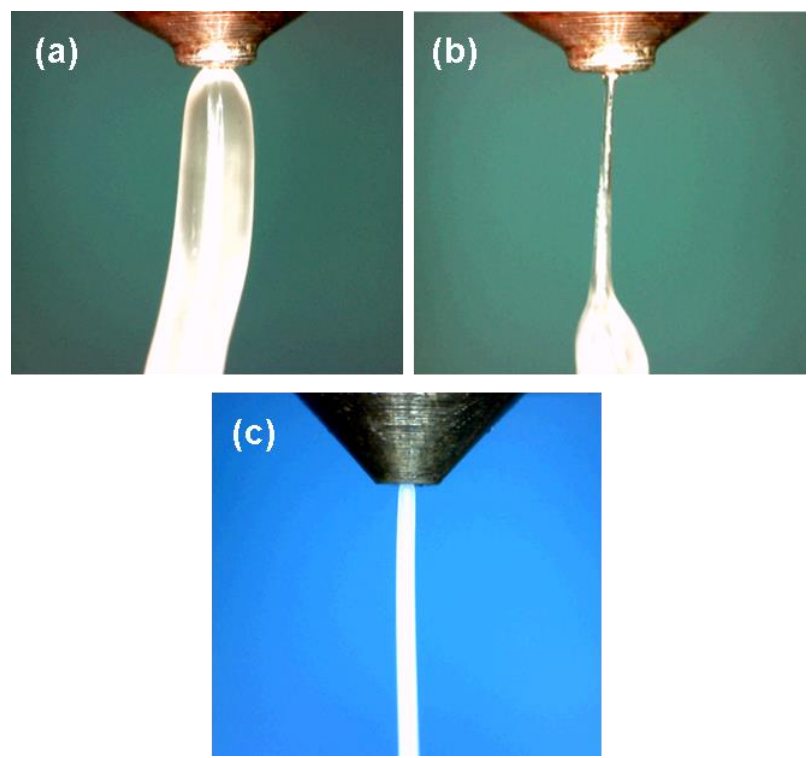

Fig. 6. (a)Extrusion of HMS-PP with a $0,4 \mathrm{~mm}$ nozzle at $200{ }^{\circ} \mathrm{C}$ set temperature under gravitational force, (b)Extrusion of HMS-PP with a $0,4 \mathrm{~mm}$ nozzle at $200{ }^{\circ} \mathrm{C}$ set temperature while pulling down the fused filament, (c) Extrusion of ABS with a $0,4 \mathrm{~mm}$ nozzle at $243{ }^{\circ} \mathrm{C}$ set temperature under gravitational force.

The 1,75 mm filament showed similar behavior in the printer as the thicker filament in the simulation: lower temperatures, between $180{ }^{\circ} \mathrm{C}$ and $200{ }^{\circ} \mathrm{C}$ as well as slow extruding speeds of $0,5 \mathrm{rpm}$ led to faster solidification and smoother filaments with less curling and surface roughness or diameter variation than higher temperatures and faster extrusion speeds.

To overcome the problem of connecting the molten filament to the platform, which was tempered at $130{ }^{\circ} \mathrm{C}$, masking tape was applied to increase the surface roughness. Still the initial connection point had to be supported using a tweezer and the printed material only stuck to the platform as long as it was liquid, but the congealed parts detached easily.

Raising the extrusion temperature to $240{ }^{\circ} \mathrm{C}$ resulted in an improvement of forming the initial connection and the printed line stuck to the plate for a longer time since it took longer to congeal. That is why the line did not detach during printing but only in the intent to stop printing and disconnect the nozzle vertically from the extruded material. So the extruder had to be moved further horizontally in printing direction to enable disconnecting without detaching the whole printed line.

In the section of supporting information a video is included demonstrating the final success of printing a second line on top of the first one, which resulted in a very good compound due to the high printing temperatures. The only problem was maintaining the initial layer in place, so this has to be further improved in following studies.

\section{Conclusion}

The comparison of the time sweep allowed the conclusion that HMS-PP is more stable by showing less variation during the studied period of two hours. ABS degrades by chain scission and cross-linking mechanism due to the 
thermal energy [5] while HMS-PP builds further interconnections activated through the elevated temperature because of butadiene monomer residues still present in the grafted copolymer [6]. The master curves of ABS concluded that data measured at $250^{\circ} \mathrm{C}$ deviates significantly from the curves derived from measurements at lower temperatures. In particular, the storage modulus and complex viscosity data of ABS $250{ }^{\circ} \mathrm{C}$ could not be used to enlarge the master curve values. HMS-PP showed a more stable behavior at the studied temperatures and all data points were suitable to create the master curves.

Comparison of the primary material with the printed material showed negligible changes in the measurement curves which could lead to the conclusion that degradation of HMS-PP during the FDM process is as low as the degradation of ABS.

ABS extrusion simulation using an FDM machine with J-Head extruder and $0.4 \mathrm{~mm}$ nozzle-diameter led to the parameters of $243^{\circ} \mathrm{C}$ extrusion temperature and optimal printing speed of 60 to $80 \mathrm{~mm} / \mathrm{min}$ while the fused filament length and diameter were depending on the extrusion speed.

Adapted extrusion parameters for HMS-PP resulted to be a minimum nozzle-diameter of $0.4 \mathrm{~mm}$ nozzlediameter optimal extrusion speed of $0.5 \mathrm{rpm}$ and temperatures between $200{ }^{\circ} \mathrm{C}$ and $240{ }^{\circ} \mathrm{C}$, dependent on the desired speed of solidification. To achieve a good connection of the material to the printer platform $240{ }^{\circ} \mathrm{C}$ are necessary. Gravitational force and oozing resulted to show a large impact on ABS extrusion while HMS-PP was not influenced by these circumstances.

\section{References}

1. Jo, W.; Chu, K. S.; Lee, H. J.; Moon, M. 3D and 4D Printing Technologies: An Overview, Material Matters, 2016, 11.2

2. Dudek, P.; Archives of Metallurgy and Materials, 2013, 58.4, 1415.

DOI: $\underline{10.2478 / \mathrm{amm}-2013-0186}$

3. Adams, M.E.; Buckley, D.J.; Colborn, R.E.; Acrylonitrilebutadiene-styrene Polymers; iSmithers Rapra Publishing, 1993.

4. Ahn, S.; Montero, M.; Odell, D.; Roundy, S.; Wright, P.; Rapid Prototyping Journal, 2002, 8.4, 248.

DOI: $10.1108 / 13552540210441166$

5. Boldizar, A.; Möller K.; Elsevier, 2003, 81.2, 359. DOI: $10.1016 / \mathrm{S} 0141-3910(03) 00107-1$

6. Klimke, K.; Braun, H., EP2679630A1, 2014.

7. Mezger, T.G.; The Rheology Handbook, $4^{\text {th }}$ Ed.; Vincentz Network, 2014.

8. Aagaard, S.; Rabenow, L. FDM Test Bench, 2015. (Internal report. Institut for MekaniskTeknologi- DTU)

9. http://wanhao3dprinter.eu/wpcontent/uploads/2014/03/Duplicator_4_4X_User_Manual.pdf, visited 2015/12/04

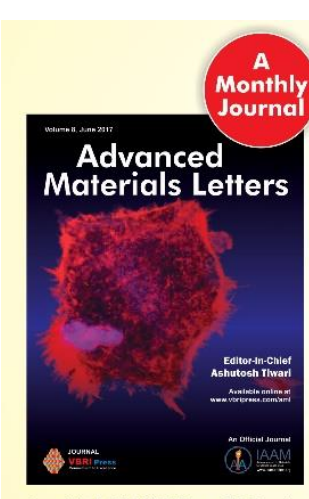

Copyright $\odot 2017$ VBRI Press AB, Sweden

\section{Publish} your article in this journal

Advanced Materials Letters is an official international journal of International Association of Advanced Materials (IAAM, www.iaamonline.org) published monthly by VBRI Press AB from Sweden. The journal is intended to provide high-quality peer-review articles in the fascinating field of materials science and technology particularly in the area of structure, synthesis and processing,
characterisation, advanced-state properties and characterisation, advanced-state properties and
applications of materials. All published articles are indexed in various databases and are available download for free. The manuscript management system is completely electronic and has fast and fair peer-review process. The journal includes review article, research article, notes, letter to editor and short communications.

www.vbripress.com/aml 


\section{Supplementary Information}
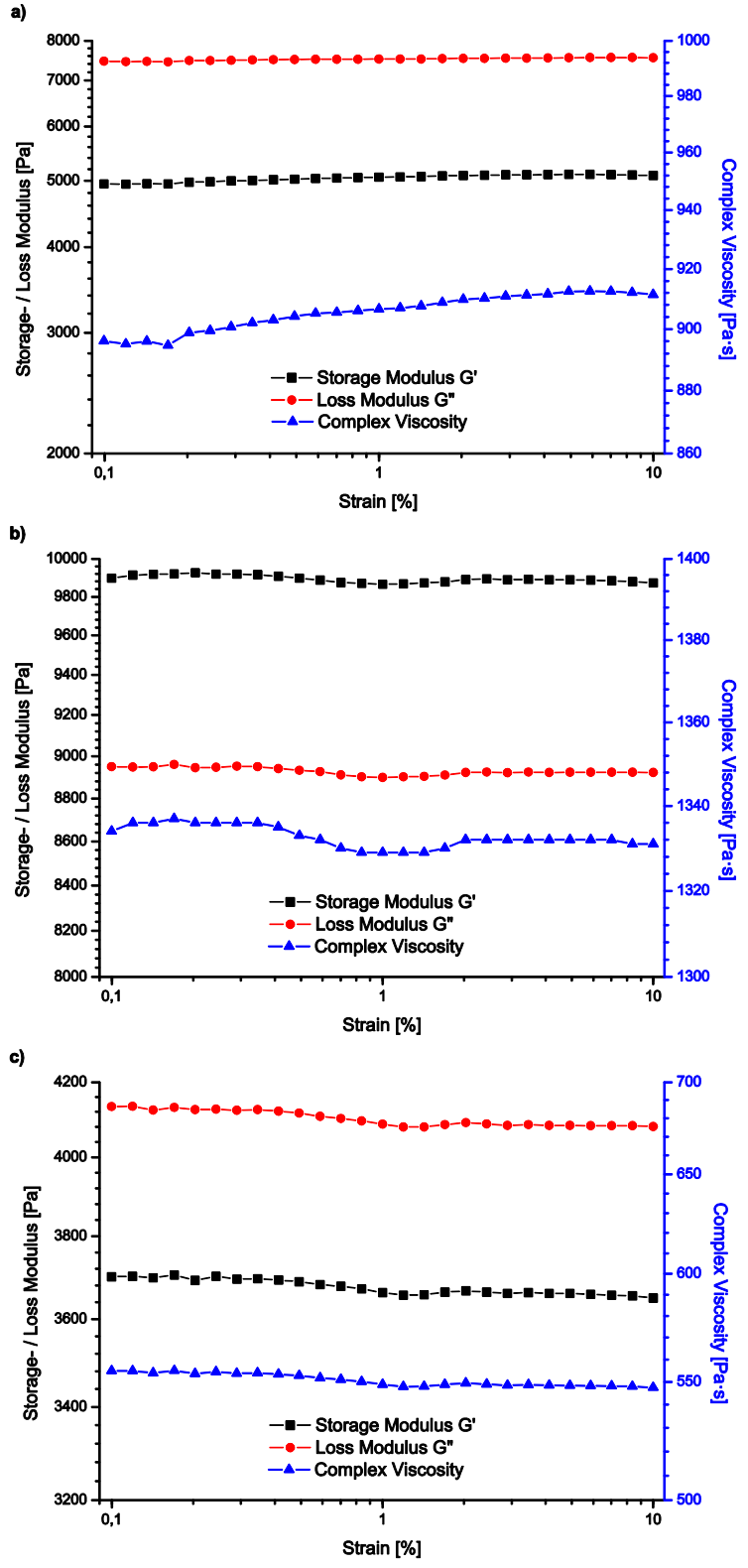

Fig. I. (a)Amplitude sweep of ABS at $250{ }^{\circ} \mathrm{C}$, (b)Amplitude sweep of HMS-PP at $170{ }^{\circ} \mathrm{C}$, (c) Amplitude sweep of HMS-PP at $250{ }^{\circ} \mathrm{C}$.
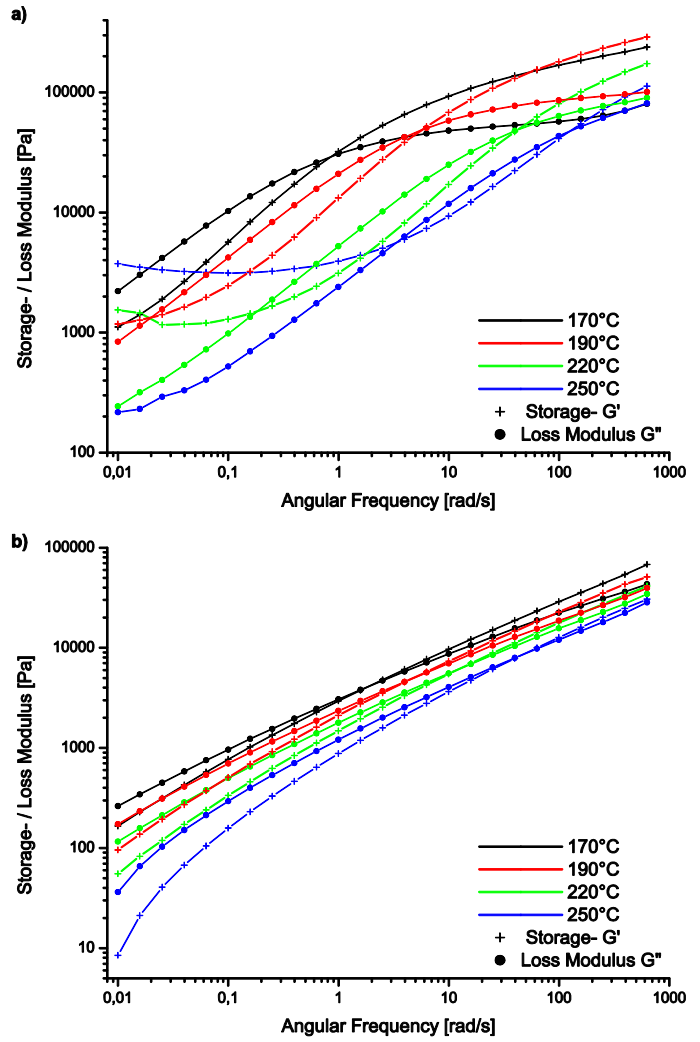

Fig. II. (a) Frequency sweeps of ABS measured at $170{ }^{\circ} \mathrm{C}, 190{ }^{\circ} \mathrm{C}$, $220^{\circ} \mathrm{C}$ and $250^{\circ} \mathrm{C}$, (b) Frequency sweeps of HMS-PP measured at $170{ }^{\circ} \mathrm{C}, 190{ }^{\circ} \mathrm{C}, 220^{\circ} \mathrm{C}$ and $250{ }^{\circ} \mathrm{C}$. Because of the thermo-rheological simple behavior the rheological curves could be shifted according to the time temperature superposition principle to form a single master curve each.

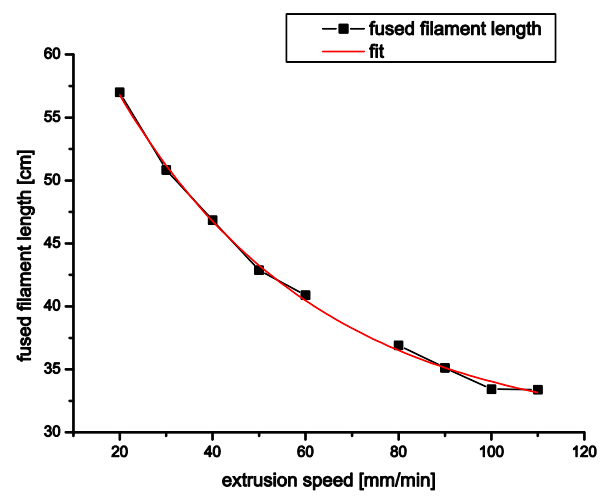

Fig. III. Connection of extrusion speed to fused filament length for ABS at $243{ }^{\circ} \mathrm{C}$ extrusion temperature. 